\title{
The impact of socioeconomic status on HPV infection among young Brazilians in a nationwide multicenter study
}

\author{
Natália L. Kops ${ }^{\text {a, }}$ Jaqueline D.C. Horvath ${ }^{\text {a }}$, Marina Bessel ${ }^{a}$, Flavia M.A. Souza ${ }^{\mathrm{b}}$, \\ Adele S. Benzaken ${ }^{\text {c, d,e }}$, Gerson F.M. Pereira ${ }^{\mathrm{b}}$, Luisa L. Villa ${ }^{\mathrm{f}}$, Eliana M. Wendland ${ }^{\mathrm{a}, \mathrm{g},{ }^{*}}$ \\ ${ }^{\text {a }}$ Hospital Moinhos de Vento, Porto Alegre, Brazil \\ ${ }^{\mathrm{b}}$ Department of Chronic Conditions and Sexually Transmitted Infections, Ministry of Health, Brasília, Distrito Federal, Brazil \\ c Tropical Medicine Foundation Heitor Vieira Dourado, Manaus, Brazil \\ ${ }^{\mathrm{d}}$ Aids Health Care Foundation, Manaus, Brazil \\ e Global Aids Healthcare Foundation, Brazil \\ ${ }^{\mathrm{f}}$ Universidade de São Paulo and Instituto do Câncer do Estado de São Paulo (ICESP), São Paulo, Brazil \\ ${ }^{g}$ Federal University of Health Sciences of Porto Alegre, Graduate Program in Health Sciences and Pediatrics, Porto Alegre, Brazil
}

\section{A R T I C L E I N F O}

\section{Keywords:}

Papillomavirus infections

Social class

Social determinants of health

Brazil

Cross-sectional studies

Young adult

\begin{abstract}
A B S T R A C T
The aim of this study is to evaluate genital human papillomavirus (HPV) infection according to socioeconomic categories in Brazil. This cross-sectional, nationwide study included 7,694 sexually active women and men aged 16-25 years. Individuals of all socioeconomic groups in all 26 Brazilian capitals and the Federal District were enrolled through public primary care units between September 2016 and November 2017. All participants answered a standardized interview administered by trained primary care health professionals. Socioeconomic class was analyzed using a pricing classification system for the Brazilian public that divides the market exclusively in terms of economic class based on the ownership of assets and the education level. Cervical samples were obtained using a Digene ${ }^{\circledR}$ HC2 DNA Collection, and penile/scrotum samples were obtained using a wet Dacron swab. HPV typing (overall and high-risk) was performed in a central lab. Of the 7,694 participants (47.85\% women), $17.92 \%$ belonged to class A-B, $56.08 \%$ to class C, and $26.00 \%$ to class D-E. The prevalence of overall HPV was similar among the social classes: $51.16 \%$ for classes A-B, $53.39 \%$ for class C, and $55.47 \%$ for classes D-E $(P=0.479)$. Similar results were found for high-risk HPV. After adjustments, the presence of HPV in individuals with a brown skin color belonging to classes A-B was 57.00\% higher [prevalence ratio 1.57 (95\%: 1.23, 2.01)] than that in whites and had no impact on the other social classes. In conclusion, HPV infection affects all socioeconomic classes in Brazil, evidencing the importance of offering the HPV vaccine to the entire population.
\end{abstract}

\section{Introduction}

Sexually transmitted infections (STIs) remain strongly associated with socioeconomic and racial/ethnic disparities (Harling et al., 2013). The human papillomavirus (HPV) is the most prevalent STI, and virtually all sexually active individuals will acquire HPV infection in their lifetimes (Chesson et al., 2014). This virus has more than 150 strains and is a recognized cause of several types of cancer, with cervical cancer being the most common among women and oropharyngeal cancer being the most common among men (Van Dyne et al., 2018; Suk et al., 2018).

Inequalities in the incidence of cancer have been reported globally, and higher rates of HPV-associated cancers have been reported in developing or underdeveloped countries (Bray et al., 2015; Ferlay et al., 2018; Benard et al., 2008). The majority of cervical cancers occur in lowand middle-income countries that lack organized screening and HPV vaccination programs (Cohen et al., 2019). In the United States, the rates of cervical carcinoma were higher among Hispanic and black individuals than among white individuals in 2015, suggesting that the health care delivery needs of some groups are not fully met (Van Dyne et al., 2018). Social disadvantage is associated with increased morbidity and mortality, but the relationships between social stratification and health are complex (Myer et al., 2004).

\footnotetext{
* Corresponding author at: Rua Ramiro Barcelos 910, Porto Alegre, Brazil, CEP 90035-004. Telephone +5533143600

E-mail addresses: natalia.kops@hmv.org.br (N.L. Kops), jaqueline.horvath@hmv.org.br (J.D.C. Horvath), marina.bessel@hmv.org.br (M. Bessel), flavia.moreno@

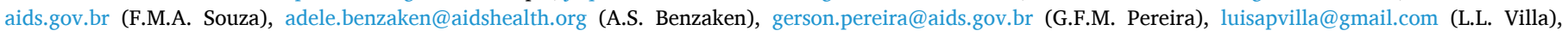
elianawend@gmail.com (E.M. Wendland).
} 
The prevalence of HPV infection also varies ethnically, economically, and educationally (Shi et al., 2014; Lin et al., 2015; Banister et al., 2015). Sexual risk behaviors, such as age of first sex and number of sexual partners, are the main risk factor associated with the acquisition and persistence of HPV infection and development of HPV-associated cancers (Rettig et al., 2015). Previous studies have shown that these sexual risk factors vary by socioeconomic status, age, race, and education level (Halpern and Haydon, 2012). Even so, there is a dearth of information about the prevalence of HPV in different socioeconomic contexts.

Brazil covers a large portion of the South American continent, and there are widespread regional and social inequalities in this country (Paim et al., 2011). An HPV immunization program using a quadrivalent vaccine was introduced in 2014 to the public health system in Brazil (Ministério da Saúde, 2018). In general, investigation of social conditions and their association with HPV infection allows for the identification of populations that need greater preventive attention, healthcare and surveillance. Therefore, this study aimed to evaluate genital HPV infection according to socioeconomic categories in Brazil.

\section{Methods}

This study is a cross-sectional, nationwide, multicenter study (POPBrazil) involving 7,694 sexually active women and men aged 16-25 years who use the public health system. Individuals from all socioeconomic groups in all 26 Brazilian capitals and the Federal District of Brasília were enrolled through public primary care units. The study protocol was published (Wendland et al., 2018).

The primary care professionals were trained and certified by the central coordinator of this study using a simulated interview and sample collection to obtain quality and reproducible data for all cities. The participants were recruited between September 2016 and November 2017 from 119 public primary health care units. Pregnant women, those who delivered a baby in the last 3 months, those who had undergone a hysterectomy or cervicectomy and those who had ever had cervical intraepithelial neoplasia grade 2 or higher were excluded, as were HPVvaccinated individuals.

All participants answered a standardized questionnaire based on validated instruments. Socioeconomic class was analyzed by using the Brazilian Criteria of Economic Classification, a pricing classification system of the Brazilian public that divides the market exclusively in terms of economic class based on the ownership of assets and the education level of the householder (Associação Brasileira de Empresas de Pesquisa, 2018). All possessions are scored, and each class is defined by the sum of these scores. This criterion divides classes into the following groups: A, B1, B2, C, C2, and D-E. For analysis, social classes were grouped into three categories: A-B, C, and D-E. This social class structure reflects a monthly household income of R \$768 (US\$202) for classes D-E, $\mathrm{R} \$ 2165$ (US\$ 569) for class C, and R $\$ 11664$ (US\$ 3069) for classes A-B (Associação Brasileira de Empresas de Pesquisa, 2018). Participants also self-declared race/skin color (white, black, yellow, brown, and indigenous) and were asked about relationship status (single, dating, married/ living with partner, or widowed/divorced/separated), educational level, alcohol and cigarette consumption, condom use, age at first intercourse, and number of sexual partners in the last year. The occurrence of STIs throughout life was also obtained by self-report. We asked if the participants ever had syphilis, gonorrhea, genital herpes, genital warts (Condyloma acuminatum), or other sexual infections.

After the interview, samples from cervical or penile/scrotal sites were collected from each participant. Cervical samples were obtained using a Digene ${ }^{\circledR}$ HC2 DNA Collection Device (Qiagen, Netherlands) and placed in $1 \mathrm{~mL}$ of Specimen Transport Medium, according to the manufacturer's instructions. Penile (penile shaft, glans penis/coronal sulcus) and scrotum samples were self-collected using a Dacron swab (Qiagen) previously moistened with a sterile saline solution. Collection was performed by intensely pressing and rubbing the swab on the epithelium
(Wendland et al., 2018).

In a certified lab, HPV detection and typing were performed using Linear Array ${ }^{\circledR}$ HPV Genotyping Test (Roche Diagnostics), which is based on polymerase chain reaction amplification (450-bp fragment of the polymorphic region of the HPV L1 gene), followed by specific hybridization and colorimetric detection. Amplification of human $\beta$-globin (biotinylated primers $\mathrm{GH} 2 \mathrm{O}$ and PC04, $268 \mathrm{bp}$ ) was performed as an internal control.

HPV results were grouped as positive for high-risk HPV $(16,18,31$, $33,35,39,45,51,52,56,58,59$, and 68 ) or positive for any HPV type (high-risk or 6, 11, 26, 40, 42, 53, 54, 55, 61, 62, 64, 66, 67, 69, 70, 71, $72,73,81,82,82 \mathrm{v}, 83,84$, and 89).

The study was approved by the Ethics Committee on Human Research (Protocol no. 1607032) at all recruitment sites. All participants provided written consent.

\subsection{Statistical analysis}

The data are described as the mean and confidence interval, frequency or absolute number. A chi-square test was used to compare proportions and a $t$-test for continuous variables; analysis of variance was used for comparisons of more than two group means. CochranArmitage Trend Test was applied to evaluate the association between the prevalence of HPV and social class. Logistic regression was used to assess the probability of high-risk HPV infection according to age (continuous variable) among different social classes. Data are shown as predicted probability and confidence intervals (CIs).

Univariate analysis was performed to observe the association between HPV and skin color by social class (Model 1). Additionally, associations between HPV infection (all HPV and high-risk HPV) and skin color stratified by social class were investigated through the construction of a Poisson regression model with robust variance. Known risk factors for HPV infection were included in the models: Model 2 involved sex, current age ( $<22$ or $\geq 22$ years old) and relationship status; for Model 3, smoking status and alcohol consumption were added to Model 2; for Model 4, more than 2 partners in the last year, self-reported STI, and age at first sexual intercourse were added to Model 3. An additional analysis was performed including region in the models. The interaction between race and social class was analyzed through Wald test.

A study sample of 7,935 was calculated to detect an HPV prevalence of at least $30 \%$ with an $80 \%$ power. The sample size was purposely equal in all regions to maximize diversity in less-populated areas, and it was weighted by the Brazilian population of each region during analyses. Males were designedly included in ratio 1:6 (M:F) to allow subsequent assessment of herd immunity as a result of the HPV vaccination program in future years. The statistical analysis was performed using SAS software, version 9.4 (Statistical Analysis System, SAS Institute Inc., Cary, $\mathrm{NC}$ ), and statistical significance was defined as $P<0.05$.

\section{Results}

A total of 7,694 participants were included (47.85\% women). Of these, $17.92 \%$ (95\% CI: $16.32 \%, 19.51 \%$ ) belonged to class A-B, $56.08 \%$ (95\% CI: $54.05 \%, 58.12 \%$ ) to class C, and $26.00 \%$ (95\% CI: $24.27 \%$, $27.73 \%$ ) to class D-E. More women belonged to social class D-E than did men $(60.37 \%$ vs. $39.63 \%, P<0.001)$ (Table 1$)$. In total, $56.79 \%(95 \%$ CI: $54.72 \%, 58.85 \%)$ self-declared as brown. The prevalence of brown skin color was higher $(P<0.001)$ among individuals in class D-E (61.55\%) than among those in classes C (57.31\%) and A-B (48.22\%). Class A-B showed a higher proportion of whites (35.20\%) than did the other classes. Regarding education level, we observed a disproportion between the social classes, whereby almost half $(45.61 \%)$ of the participants with university-level or higher education belonged to class A-B, whereas $20.45 \%$ belonged to class C and $6.73 \%$ to class D-E. Although a higher proportion of participants in class A-B than those in other classes had two or more sexual partners in the last year $(40.13 \%$ vs. $32.36 \%$ vs. 
Table 1

Characteristics of the participants 16-25 years old included in the POP-Brazil study, according to socioeconomic status. Brazil 2016-2017.

\begin{tabular}{|c|c|c|c|c|c|}
\hline Characteristics & n (\%) & $\begin{array}{l}\text { A-B } \\
1,444\end{array}$ & $\begin{array}{l}\mathrm{C} \\
4,098\end{array}$ & $\begin{array}{l}\mathrm{D}-\mathrm{E} \\
2,152\end{array}$ & $P$ value \\
\hline Sex & & & & & $<0.001$ \\
\hline Female & $\begin{array}{l}5,569 \\
(47.85)\end{array}$ & 33.83 & 46.52 & 60.37 & \\
\hline Age, $y$ & & & & & 0.446 \\
\hline $16-17$ & $\begin{array}{l}681 \\
(10.94)\end{array}$ & 11.00 & 11.72 & 9.18 & \\
\hline $18-19$ & $\begin{array}{l}1,767 \\
(21.77)\end{array}$ & 20.20 & 21.30 & 23.96 & \\
\hline $20-21$ & $\begin{array}{l}1,768 \\
(22.12)\end{array}$ & 22.38 & 22.58 & 20.88 & \\
\hline $22-23$ & $\begin{array}{l}1,713 \\
(22.54)\end{array}$ & 22.74 & 23.07 & 21.20 & \\
\hline $24-25$ & $\begin{array}{l}1,765 \\
(22.63)\end{array}$ & 23.68 & 21.33 & 24.78 & \\
\hline Race/color ${ }^{\mathrm{a}}$ & & & & & $<0.001$ \\
\hline White & $\begin{array}{l}1,857 \\
(23.95)\end{array}$ & 35.20 & 24.51 & 15.04 & \\
\hline Black & $\begin{array}{l}1,200 \\
(16.77)\end{array}$ & 14.50 & 15.58 & 20.86 & \\
\hline Brown/pardo & $\begin{array}{l}4,413 \\
(56.79)\end{array}$ & 48.22 & 57.31 & 61.55 & \\
\hline $\begin{array}{l}\text { Other (Asiatic, } \\
\text { indigenous) }\end{array}$ & $180(2.49)$ & 2.08 & 2.60 & 2.55 & \\
\hline Education level $^{\mathrm{a}}$ & & & & & $<0.001$ \\
\hline Elementary school & $\begin{array}{l}1,613 \\
(23.54)\end{array}$ & 6.61 & 19.64 & 43.55 & \\
\hline Secondary school & $\begin{array}{l}4,304 \\
(55.06)\end{array}$ & 47.79 & 59.91 & 49.72 & \\
\hline Graduate & $\begin{array}{l}1,776 \\
(21.40)\end{array}$ & 45.61 & 20.45 & 6.73 & \\
\hline Monthly income $\mathrm{a}^{\mathrm{a} b \mathrm{~b}}$ & & & & & $\begin{array}{l}< \\
0.001\end{array}$ \\
\hline$<\mathrm{R} \$ 830$ & $\begin{array}{l}1,369 \\
(22.42)\end{array}$ & 58.73 & 18.39 & 5.33 & \\
\hline $\mathrm{R} \$ 830-\mathrm{R} \$ 1659$ & $\begin{array}{l}1,325 \\
(19.05)\end{array}$ & 3.86 & 15.75 & 37.18 & \\
\hline $\mathrm{R} \$ 1660-\mathrm{R} \$ 2489$ & $\begin{array}{l}2,937 \\
(39.93)\end{array}$ & 16.72 & 43.74 & 48.1 & \\
\hline$>\mathrm{R} \$ 2490$ & $\begin{array}{l}1,234 \\
(18.60)\end{array}$ & 20.67 & 22.12 & 9.36 & \\
\hline Marital status ${ }^{a}$ & & & & & $\begin{array}{l}< \\
0.001\end{array}$ \\
\hline $\begin{array}{l}\text { Single/widowed/ } \\
\text { divorced/separated }\end{array}$ & $\begin{array}{l}2,944 \\
(41.54)\end{array}$ & 54.96 & 41.95 & 31.39 & \\
\hline Dating & $\begin{array}{l}2,906 \\
(34.24)\end{array}$ & 14.34 & 34.33 & 47.68 & \\
\hline $\begin{array}{l}\text { Married/living with } \\
\text { partner }\end{array}$ & $\begin{array}{l}1,843 \\
(24.22)\end{array}$ & 30.70 & 23.74 & 20.93 & \\
\hline Lifetime condom use & $\begin{array}{l}3,914 \\
(50.70)\end{array}$ & 59.88 & 52.29 & 41.08 & $<0.001$ \\
\hline Same sex experience & $378(7.62)$ & 11.54 & 7.80 & 4.60 & $<0.001$ \\
\hline $\begin{array}{l}\text { No. sex partners in the past } \\
\text { year }^{\mathrm{a}}\end{array}$ & & & & & 0.003 \\
\hline$<2$ & $\begin{array}{l}5,250 \\
(67.01)\end{array}$ & 59.87 & 67.64 & 70.49 & \\
\hline$\geq 2$ & $\begin{array}{l}2,107 \\
(32.99)\end{array}$ & 40.13 & 32.36 & 29.51 & \\
\hline
\end{tabular}

a Does not sum to 7,694 because some of the responses are missing.

b US\$1 is equivalent to $\mathrm{R} \$ 3.80$.

$29.51 \%, P=0.003)$ and more same sex experiences, these individuals also cited condom use more frequently. Age [prevalence ratio (PR) $21.57 \%$ (95\% CI: 21.45, 21.68)], the percentage of smokers [PR 15.66\% (95\% CI: 14.07, 17.25)], and self-reported STI (12.74\%) were similar among the different social classes (data not shown).

In total, 5,268 women and 1,120 men provided valid samples for HPV detection $(6,388)$. Although there was an increase in the prevalence of overall HPV among the lowest social class when compared to the highest social class, this tendence was no significant: $51.16 \%$ among class A-B, $53.39 \%$ among class C, and $55.47 \%$ among class D-E ( $P=$ 0.479). The same scenario was found for high-risk HPV types $(30.52 \%$,
$35.18 \%$, and $37.96 \%, P=0.263$, respectively) and for HPV multiple infection, defined as infected with at least two high-risk HPV types (10.34\%, $11.73 \%$, and $12.52 \%$, respectively $P=0.510$ ) (Fig. 1 ). In women, no significant differences were found comparing the prevalence of overall HPV (A-B: 52.04\%; C: 55.46\%; D-E: 54.18\%; $P=0.541$ ) and high-risk HPV (A-B: $34.83 \%$; C: $39.70 \%$; D-E: $38.23 \%$; $P=0.279$ ) between social classes. There was also no significant difference in men (AB: $50.32 \%$; C: $50.06 \%$; D-E: $59.56 \%$; $P=0.330$ and A-B: $26.44 \%$; C: 27.90\%; D: 37.08; $P=0.234$, respectively).

Moreover, when high-risk HPV types were analyzed individually, the distribution among social classes was similar (Fig. 2). Indeed, only two viral types were significantly different between social classes: HPV 33 was more prevalent in class C $(2.18 \%, P=0.012)$ and HPV 45 more prevalent in class D-E $(3.82 \%, P=0.005)$.

The probability of high-risk HPV infection according to age does not vary significantly in the higher socioeconomic classes. However, in the lower classes (C and D-E), the probability of high-risk HPV infection was significantly lower with increasing age (Fig. 3).

To evaluate the association between skin color and HPV prevalence in different social classes, a model was constructed to estimate the prevalence ratio of infection stratified by social class (Table 2). After adjustments, the prevalence of HPV was $57.00 \%$ higher in self-reported brown individuals of class A-B than in whites [PR 1.57 (95\% CI: 1.23, 2.01)]. In classes $C$ and D-E, infection was not significantly different between skin color types. When assessing the PR of high-risk HPV infection, no significant differences were found between color and social classes after adjusting for the same variables (Table 3 ). When region was included in the model, there was no change on the prevalence of overall and high-risk HPV by skin color among social classes (data not shown). Furthermore, there was no significative interaction between race and social class for overall $(\mathrm{p}=0.116)$ or high-risk HPV infection $(\mathrm{p}=0.553)$ (data not shown).

\section{Discussion}

This study is the first with a nationwide sample that included young adults of both sexes with a diversity of social classes and skin colors to evaluate the distribution of HPV by different socioeconomic groups in Brazil. Overall, there was no significant difference in the prevalence of HPV (overall and high-risk) among social classes. Skin color was an important factor for infection among social class A-B, with a higher prevalence of overall HPV, but not high-risk infection, among brown individuals than among those with white skin color.

Socioeconomic and racial or ethnic disparities have been associated with serious health conditions (Rosengren et al., 2019). The

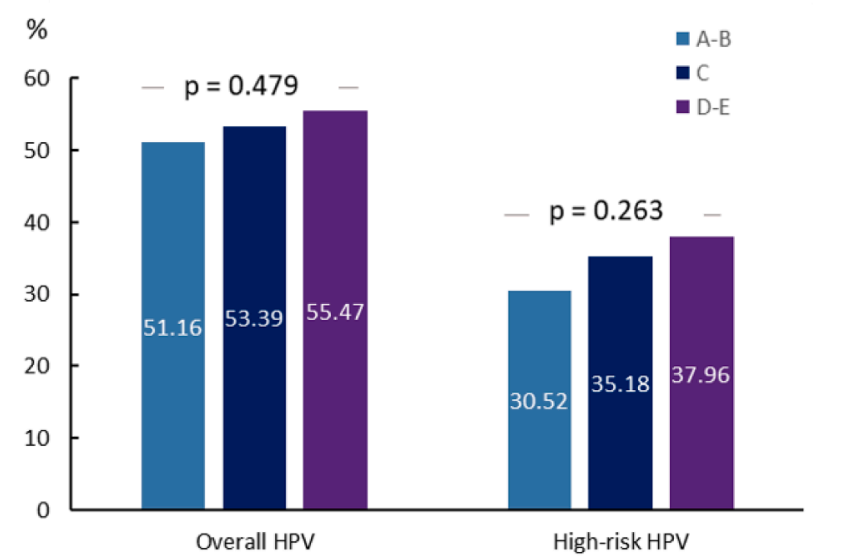

Legend: Cochran-Armitage trend test.

Fig. 1. Prevalence of overall and high-risk HPV types among different social classes. Cochran-Armitage trend test. 


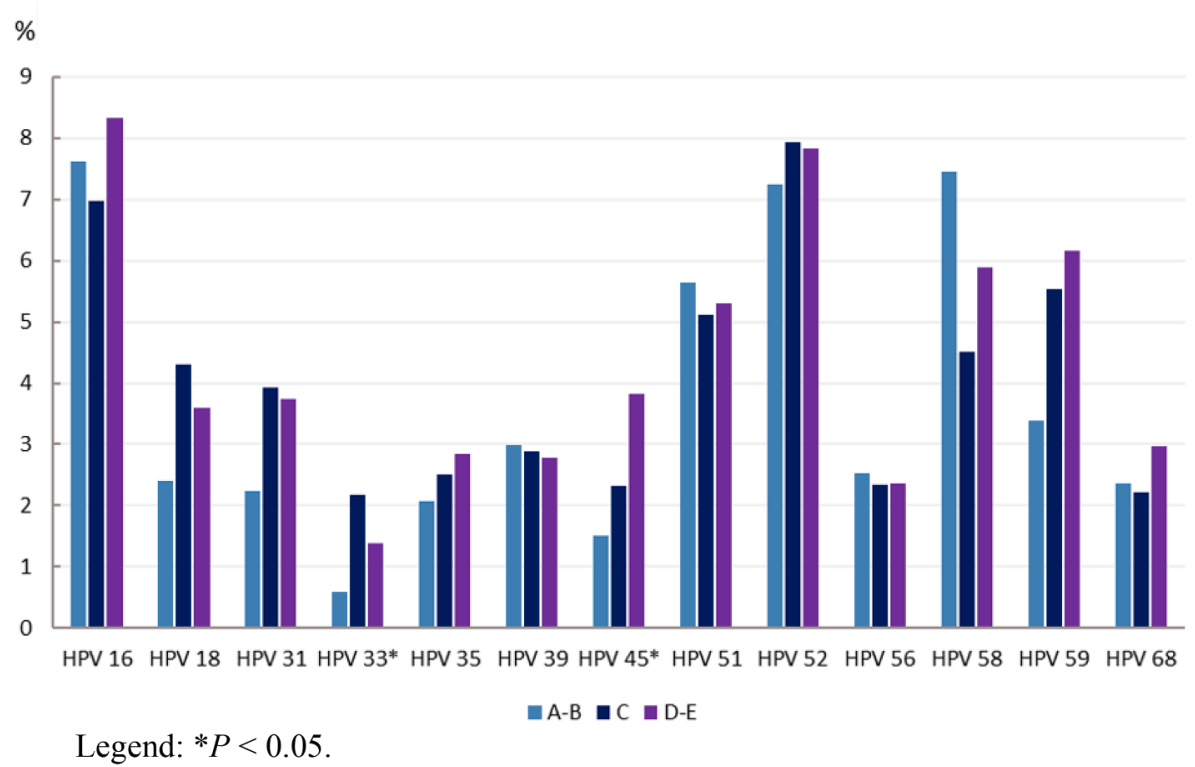

Fig. 2. Prevalence of high-risk HPV types among Brazilian young adults according to their social class. $* P<0.05$.
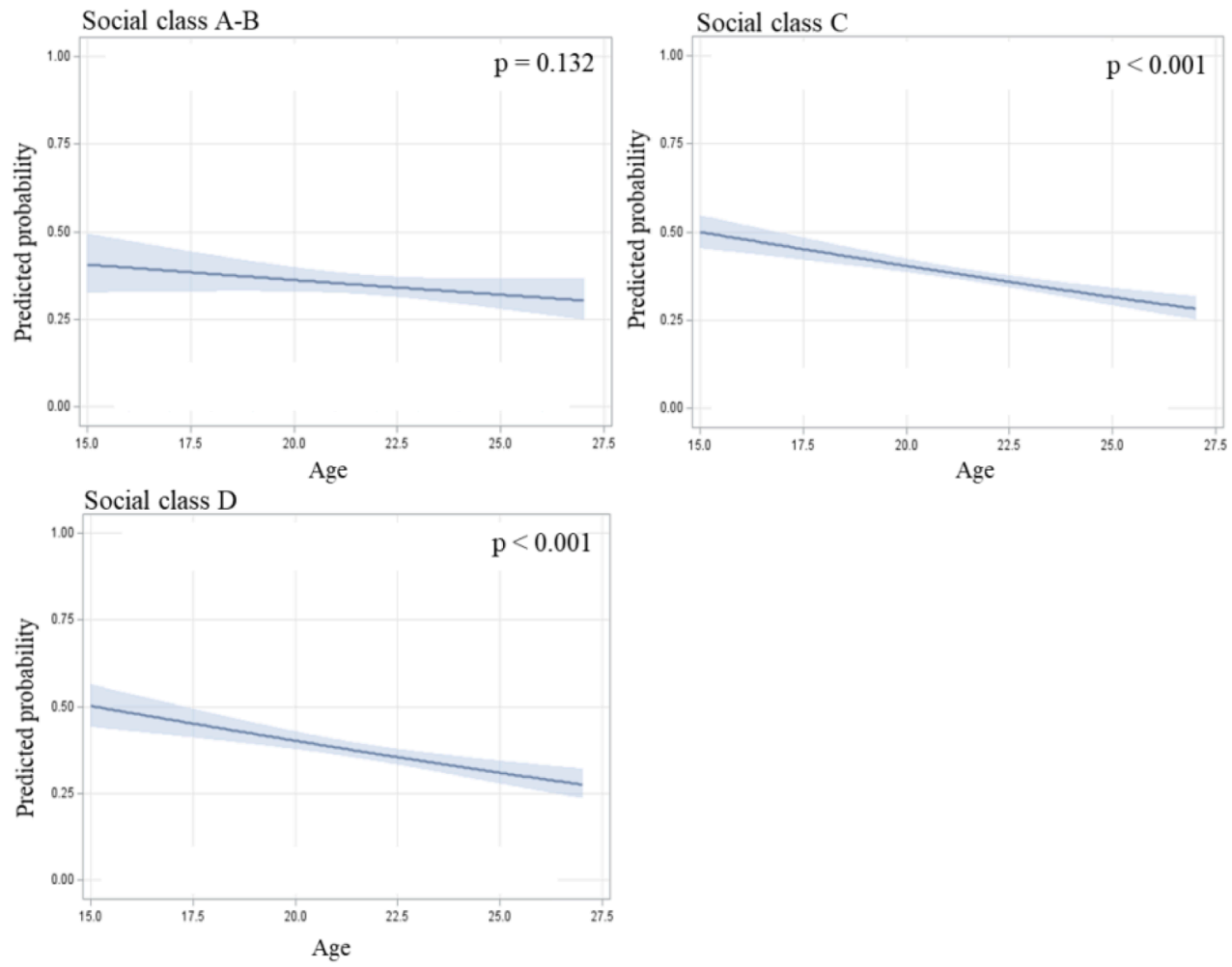

Legend: Data are shown as predicted probability and confidence interval. $* P<0.05$.

Fig. 3. Probability of high-risk HPV infection according to age among different social classes. Data are shown as predicted probability and confidence interval. ${ }^{*} P$ $<0.05$.

socioeconomic position of an individual influences the prevalence of health-related behaviors known to be strong risk factors for morbidity and premature mortality, such as smoking, diet, exercise, and alcohol and drug use (Braveman et al., 2011). A low socioeconomic status and its correlates, such as a lower educational level, reduce life opportunities, suggesting that such individuals have markedly poorer health care (Rosengren et al., 2019) and might not be able to afford necessary health care or might live in neighborhoods with poor access to healthcare facilities, which can lead to vulnerability to the development of disease. Furthermore, evidences have suggested that skin color and social class interact in complex ways to influence health, and the magnitude of association between social class and health varies according to skin color. In multiracial societies like Brazil, color is preferred because depict better the continuous aspect of phenotypes (Travassos and Williams, 2004; Telles, 2002).

We could not find other studies evaluating the prevalence of HPV 
Table 2

Overall HPV infection by skin color among social classes.

\begin{tabular}{|c|c|c|c|c|c|c|c|c|}
\hline \multirow[t]{2}{*}{ Social class } & \multicolumn{2}{|c|}{ Model 1} & \multicolumn{2}{|c|}{ Model 2} & \multicolumn{2}{|c|}{ Model 3} & \multicolumn{2}{|c|}{ Model 4} \\
\hline & PR & $95 \%$ CI & PR & $95 \% \mathrm{CI}$ & PR & $95 \%$ CI & $\mathrm{PR}$ & $95 \%$ CI \\
\hline \multicolumn{9}{|l|}{ A-B } \\
\hline White & 1 & & 1 & & 1 & & 1 & \\
\hline Black & 1.37 & $0.98,1.91$ & 1.34 & $0.97,1.88$ & 1.33 & $0.96,1.84$ & 1.40 & $0.99,1.99$ \\
\hline Brown & 1.39 & $1.08,1.78^{*}$ & 1.39 & $1.08,1.78^{*}$ & 1.44 & $1.12,1.84 *$ & 1.57 & $1.23,2.01 *$ \\
\hline Others & 0.97 & $0.45,2.08$ & 0.95 & $0.44,2.07$ & 0.93 & $0.43,1.99$ & 1.05 & $0.42,2.62$ \\
\hline \multicolumn{9}{|l|}{$\mathrm{C}$} \\
\hline White & 1 & & 1 & & 1 & & 1 & \\
\hline Black & 0.95 & $0.78,1.14$ & 0.92 & $0.77,1.11$ & 0.92 & $0.77,1.11$ & 0.93 & $0.77,1.12$ \\
\hline Brown & 1.03 & $0.89,1.18$ & 1.03 & $0.89,1.18$ & 1.03 & $0.90,1.19$ & 1.01 & $0.88,1.17$ \\
\hline Others & 1.02 & $0.68,1.54$ & 0.99 & $0.67,1.45$ & 1.02 & $0.70,1.51$ & 1.02 & $0.72,1.44$ \\
\hline \multicolumn{9}{|l|}{$\mathrm{D}$} \\
\hline White & 1 & & 1 & & 1 & & 1 & \\
\hline Black & 1.02 & $0.78,1.33$ & 0.98 & $0.76,1.27$ & 0.96 & $0.75,1.25$ & 0.96 & $0.75,1.24$ \\
\hline Brown & 1.11 & $0.89,1.38$ & 1.09 & $0.88,1.35$ & 1.08 & $0.88,1.33$ & 1.05 & $0.85,1.29$ \\
\hline Others & 1.04 & $0.65,1.67$ & 0.99 & $0.64,1.56$ & 0.98 & $0.64,1.48$ & 0.95 & $0.59,1.50$ \\
\hline
\end{tabular}

Data are described as the prevalence ratio (PR) and the 95\% confidence interval (CI). Model 1: univariate model. Model 2: multivariate model (Poisson) adjusted for sex, current age and relationship status. Model 3: Model $2+$ smoking status and alcohol consumption. Model 4: Model $3+$ more than 2 partners in the last year, report of STI, and age at first sexual intercourse. ${ }^{*} P<0.05$.

Table 3

High-risk HPV infection by skin color among social classes.

\begin{tabular}{|c|c|c|c|c|c|c|c|c|}
\hline \multirow[t]{2}{*}{ Social class } & \multicolumn{2}{|c|}{ Model 1} & \multicolumn{2}{|c|}{ Model 2} & \multicolumn{2}{|c|}{ Model 3} & \multicolumn{2}{|c|}{ Model 4} \\
\hline & PR & $95 \% \mathrm{CI}$ & PR & $95 \% \mathrm{CI}$ & PR & $95 \% \mathrm{CI}$ & PR & $95 \%$ CI \\
\hline \multicolumn{9}{|l|}{ A-B } \\
\hline White & 1 & & 1 & & 1 & & 1 & \\
\hline Black & 1.39 & $0.85,2.27$ & 1.36 & $0.85,2.19$ & 1.33 & $0.85,2.09$ & 1.34 & $0.84,2.14$ \\
\hline Brown & 1.23 & $0.85,1.78$ & 1.20 & $0.83,1.74$ & 1.27 & $0.88,1.84$ & 1.35 & $0.93,1.96$ \\
\hline Others & 1.06 & $0.40,2.79$ & 0.97 & $0.38,2.47$ & 0.91 & $0.36,2.32$ & 0.80 & $0.23,2.72$ \\
\hline \multicolumn{9}{|l|}{$\mathrm{C}$} \\
\hline White & 1 & & 1 & & 1 & & 1 & \\
\hline Black & 0.87 & $0.67,1.12$ & 0.83 & $0.65,1.07$ & 0.83 & $0.65,1.07$ & 0.83 & $0.65,1.08$ \\
\hline Brown & 1.01 & $0.83,1.24$ & 1.01 & $0.83,1.23$ & 1.02 & $0.84,1.24$ & 0.99 & $0.81,1.20$ \\
\hline Others & 1.05 & $0.63,1.73$ & 0.99 & $0.62,1.57$ & 1.03 & $0.65,1.64$ & 0.98 & $0.61,1.59$ \\
\hline \multicolumn{9}{|l|}{$\mathrm{D}$} \\
\hline White & 1 & & 1 & & 1 & & 1 & \\
\hline Black & 1.16 & $0.79,1.70$ & 1.12 & $0.77,1.64$ & 1.10 & $0.75,1.59$ & 1.06 & $0.74,1.52$ \\
\hline Brown & 1.20 & $0.87,1.67$ & 1.19 & $0.86,1.64$ & 1.19 & $0.86,1.64$ & 1.11 & $0.81,1.51$ \\
\hline Others & 1.31 & $0.70,2.45$ & 1.21 & $0.66,2.21$ & 1.17 & $0.66,2.05$ & 1.06 & $0.58,1.96$ \\
\hline
\end{tabular}

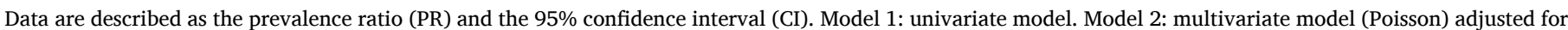

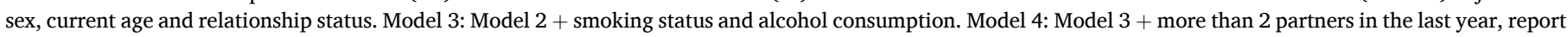
of STI, and age at first sexual intercourse. ${ }^{*} P<0.05$.

and socioeconomic status, although previous studies have reported differences according to race and ethnicity. Black women have a higher prevalence of all types of HPV (Manhart et al., 2006; Hariri et al., 2011). Some of the disparity in HPV prevalence may be related to the time variation until HPV clearance or persistent HPV infection (Hirth, 2019). Black and Hispanic women also reportedly have a higher prevalence of high-risk HPV types, excluding types 16 and 18 (Montealegre et al., 2018). In contrast to other HPV types, Black, Hispanic, and Asian women are less likely than white women to be infected with HPV 16 or 18 (Montealegre et al., 2018; Datta et al., 2006). Nonetheless, these patterns of distribution were not found in Brazil in the present study, and the prevalence of high-risk HPV, except for HPV types 33 and 45, was equally distributed across different social classes and skin colors. This lack of association could be explained by differences in sexual behaviors associated with race in these countries, which are more homogenous in Brazil, or the misclassification of skin color by the participants, preventing us from finding differences between the groups. Skin color is still linked to prejudice and violence in Brazil, which influences how people classify their skin color/race.

Although no significant association has been found between socioeconomic status and HPV, the prevalence of both overall and highrisk HPV infection has increased in the lower social classes as compared to the higher class (A-B). The HPV catch-up vaccination status seems to be higher among women with higher education level (Grandahl et al., 2017; Kellogg et al., 2019), and the coverage in high socioeconomic areas is also higher than the coverage in low socioeconomic areas (Barbaro and Brotherton, 2014). These social inequalities should influence the prevalence of HPV-associated cancers, once an inverse association between social class and HPV-associated cancers has been reported (Benard et al., 2008). Recently, nonwhite race and uninsured status were found to be associated with worse cancer-specific mortality in HPV-positive oropharyngeal squamous cell carcinoma of the head and neck (Pike et al., 2020). In 2019, the highest incidence of cervical cancer was found in the northern region of Brazil (21.20/100 thousand), followed by the northeast, central west, south, and southeast regions (INCA, 2020), and socioeconomic status may account for these disparities in cervical cancer incidence (McDougall et al., 2007). Since we found no significant difference in social class and the prevalence of HPV, these differences between cancer rates and social class must be due to the difference in access to and assistance from the health system. 
Age is a known factor strongly associated with HPV infection. Based on a meta-analysis of 78 studies, in all world regions, HPV prevalence was highest in women younger than 35 years of age, decreasing in women of older age. Furthermore, the HPV prevalence was higher in less developed than more developed countries, but both sets of countries showed a continuous decline with increasing age (de Sanjosé et al., 2007). In this study, a progressive decrease in prevalence of high-risk HPV as age increased was found only on the lower classes (C and DE). Differences in sexual behaviors between classes may explain this different pattern of HPV infection in the higher social class. Social classes A-B had higher lifetime condom use, higher number of sexual partners and same sex experience.

Brazil is a developing country with a distribution of social classes and skin color similar to those in this study $(25.2 \%$ class A-B, $47.8 \%$ class $\mathrm{C}$, and $27.0 \%$ class D-E (Associação Brasileira de Empresas de Pesquisa, 2018); 45.2\% white color, 45.1\% brown, and 8.9\% black (IBGE, 2016). Nonetheless, some limitations should be noted. Since 1988, Brazil has developed the Unified Health System (SUS), a complex health system based on the principles of health as a citizen's right and the state's duty (Paim et al., 2011). Socioeconomic disparities exist between individuals covered by public and private sectors, which indicates that rich and poor populations receive different standards of care in the Brazilian health system (Paim et al., 2011). Therefore, a strategy of recruitment that included populations from different environments, such as school, health units and domiciles, was used in this study in an attempt to include participants from all social classes, residence type, and education levels. The sample was restricted to populations from Brazilian capitals without including rural or small cities, which can exhibit differences in social distributions and behaviors. Regardless, it is unlikely that there are differences in sexual risk behavior, as previously highlighted by Moser et al. (2007). In addition, certain racial groups, such as indigenous populations and those of Asian origin, were underrepresented in the sample and analyzed together. Lastly, males had a higher rate of invalid samples as reported in previous studies because they had lower levels of DNA for testing (Machalek et al., 2017). Sampling from the skin (penile shaft and scrotum) is often composed by superficial squamous cells different from cervical samples.

This study showed that HPV affects individuals of all socioeconomic classes in Brazil, evidencing the importance of offering the HPV vaccine to the entire population. These results also highlight the significance of the direction of public health actions related to HPV, which it is essential that the actions of sexual health promotion and STI prevention are able to reach all socioeconomic classes.

\section{Declaration of Competing Interest}

The authors declare that they have no known competing financial interests or personal relationships that could have appeared to influence the work reported in this paper.

\section{Acknowledgments}

This work was supported by the Hospital Moinhos de Vento through the Program for Supporting the Institutional Development of the Public Health System (PROADI-SUS), which is supported by the Ministry of Health of Brazil.

\section{References}

Harling, G., Subramanian, S.V., Bärnighausen, T., Kawachi, I., 2013. Socioeconomic disparities in sexually transmitted infections among young adults in the United States: examining the interaction between income and race/ethnicity. Sex. Transm. Dis. 40, 575-581. https://doi.org/10.1097/olq.0b013e31829529cf.

Chesson, H.W., Dunne, E.F., Hariri, S., Markowitz, L.E., 2014. The estimated lifetime probability of acquiring human papillomavirus in the United States. Sex. Transm. Dis. 41, 660-664. https://doi.org/10.1097/OLQ.0000000000000193.

Van Dyne, E.A., Henley, S.J., Saraiya, M., Thomas, C.C., Markowitz, L.E., Benard, V.B., 2018. Trends in human papillomavirus-associated cancers - United States,
1999-2015. MMWR Morb. Mortal. Wkly Rep. 67, 918-924. https://doi.org/ 10.15585/mmwr.mm6733a2.

Suk, R., Mahale, P., Sonawane, K., Sikora, A.G., Chhatwal, J., Schmeler, K.M., et al., 2018. Trends in risks for second primary cancers associated with index human papillomavirus-associated cancers. JAMA Netw Open 1, e181999. https://doi.org/ 10.1001/jamanetworkopen.2018.1999.

Bray, F., Ferlay, J., Laversanne, M., Brewster, D.H., Gombe Mbalawa, C., Kohler, B., et al., 2015. Cancer incidence in five continents: inclusion criteria, highlights from volume $\mathrm{X}$ and the global status of cancer registration. Int. J. Cancer 137, 2060-2071. https://doi.org/10.15585/mmwr.mm6733a2.

Ferlay J., Ervik M., Mery L., Pineros M., Znaor A., Soerjomataram I., et al. Cancer Today (powered by GLOBOCAN 2018). n.d.

Benard, V.B., Johnson, C.J., Thompson, T.D., Roland, K.B., Lai, S.M., Cokkinides, V., et al., 2008. Examining the association between socioeconomic status and potential human papillomavirus-associated cancers. Cancer 113, 2910-2918. https://doi.org/ 10.1002/cncr.23742.

Cohen, P.A., Jhingran, A., Oaknin, A., Denny, L., 2019. Cervical cancer. Lancet 393, 169-182. https://doi.org/10.1016/S0140-6736(18)32470-X.

Myer, L., Ehrlich, R.I., Susser, E.S., 2004. Social epidemiology in South Africa. Epidemiol. Rev. 26, 112-123. https://doi.org/10.1093/epirev/mxh004.

Shi, R., Devarakonda, S., Liu, L., Taylor, H., Mills, G., 2014. Factors associated with genital human papillomavirus infection among adult females in the United States, NHANES 2007-2010. BMC Res. Notes 7. https://doi.org/10.1186/1756-0500-7-544.

Lin, L., Benard, V.B., Greek, A., Hawkins, N.A., Roland, K.B., Saraiya, M., 2015. Racial and ethnic differences in human papillomavirus positivity and risk factors among low-income women in Federally Qualified Health Centers in the United States. Prev. Med. 81, 258-261. https://doi.org/10.1016/j.ypmed.2015.08.027.

Associação Brasileira de Empresas de Pesquisa, (ABEP), 2018. Critério Brasil 1-6.

Banister, C.E., Messersmith, A.R., Cai, B.o., Spiryda, L.B., Glover, S.H., Pirisi, L., et al., 2015. Disparity in the persistence of high-risk human papillomavirus genotypes between African American and European American Women of College Age. J. Infect. Dis. 211 (1), 100-108. https://doi.org/10.1093/infdis/jiu394.

Rettig, E., Kiess, A.P., Fakhry, C., 2015. The role of sexual behavior in head and neck cancer: implications for prevention and therapy. Expert Rev. Anticancer Ther. 15, 35-49. https://doi.org/10.1586/14737140.2015.957189.

Halpern, C.T., Haydon, A.A., 2012. Sexual timetables for oral-genital, vaginal, and anal intercourse: sociodemographic comparisons in a nationally representative sample of adolescents. Am. J. Public Health 102, 1221-1228. https://doi.org/10.2105/ ajph.2011.300394.

Paim, J., Travassos, C., Almeida, C., Bahia, L., Macinko, J., 2011. The Brazilian health system: history, advances, and challenges. Lancet 377, 1778-1797. https://doi.org/ 10.1016/S0140-6736(11)60054-8.

Ministério da Saúde. 2018. Informe técnico da ampliação da oferta das vacinas papilomavírus humano 6, 11, 16 e 18 (recombinante) - vacina HPV quadrivalente e meningocócica C (conjugada).

Wendland, E.M., Caierão, J., Domingues, C., Maranhão, A.G.K., de Souza, F.M.A., Hammes, L.S., et al., 2018. POP-Brazil study protocol: a nationwide cross-sectional evaluation of the prevalence and genotype distribution of human papillomavirus (HPV) in Brazil. BMJ Open 8, e021170. https://doi.org/10.1136/bmjopen-2017021170.

Rosengren, A., Smyth, A., Rangarajan, S., Ramasundarahettige, C., Bangdiwala, S.I. AlHabib, K.F., et al., 2019. Socioeconomic status and risk of cardiovascular disease in 20 low-income, middle-income, and high-income countries: the Prospective Urban Rural Epidemiologic (PURE) study. Lancet Glob. Health 7 (6), e748-e760. https:// doi.org/10.1016/S2214-109X(19)30045-2.

Braveman, P.A., Egerter, S.A., Mockenhaupt, R.E., 2011. Broadening the focus the need to address the social determinants of health. Am. J. Prev. Med. 40, S4-S18. https:// doi.org/10.1016/j.amepre.2010.10.002.

Travassos, C., Williams, D.R., 2004. The concept and measurement of race and their relationship to public health: a review focused on Brazil and the United States. Cad. Saúde Públ. 20, 660-678. https://doi.org/10.1590/S0102-311X2004000300003.

Telles, E.E., 2002. Racial ambiguity among the Brazilian population. Ethnic Racial Stud. 25, 415-441. https://doi.org/10.1080/01419870252932133.

Manhart, L.E., Holmes, K.K., Koutsky, L.A., Wood, T.R., Kenney, D.L., Feng, Q., et al., 2006. Human papillomavirus infection among sexually active young women in the United States: implications for developing a vaccination strategy. Sex. Transm. Dis. 33, 502-508. https://doi.org/10.1097/01.olq.0000204545.89516.0a.

Hariri, S., Unger, E.R., Sternberg, M., Dunne, E.F., Swan, D., Patel, S., et al., 2011. Prevalence of genital human papillomavirus among females in the United States, the National Health And Nutrition Examination Survey, 2003-2006. J. Infect. Dis. 204, 566-573. https://doi.org/10.1093/infdis/jir341.

Hirth, J., 2019. Disparities in HPV vaccination rates and HPV prevalence in the United States: a review of the literature. Human Vacc. Immunother. 15, 146-155. https:// doi.org/10.1080/21645515.2018.1512453.

Montealegre, J.R., Peckham-Gregory, E.C., Marquez-Do, D., Dillon, L., Guillaud, M., Adler-Storthz, K., et al., 2018. Racial/ethnic differences in HPV 16/18 genotypes and integration status among women with a history of cytological abnormalities. Gynecol. Oncol. 148, 357-362. https://doi.org/10.1016/j.ygyno.2017.12.014.

Datta, G.D., Colditz, G.A., Kawachi, I., Subramanian, S.V., Palmer, J.R., Rosenberg, L., 2006. Individual-, neighborhood-, and state-level socioeconomic predictors of cervical carcinoma screening among U.S. black women: a multilevel analysis. Cancer 106, 664-669. https://doi.org/10.1002/cncr.21660.

Grandahl M., Larsson M., Dalianis T., Stenhammar C., Tydén T., Westerling R., et al. Catch-up HPV vaccination status of adolescents in relation to socioeconomic factors, individual beliefs and sexual behaviour. PLOS ONE 2017;12:e0187193. https://doi. org/10.1371/journal.pone.0187193. 
Kellogg, C., Shu, J., Arroyo, A., Dinh, N.T., Wade, N., Sanchez, E., et al., 2019. A significant portion of college students are not aware of HPV disease and HPV vaccine recommendations. Hum. Vac. Immunother. 15, 1760-1766. https://doi.org/ 10.1080/21645515.2019.1627819.

Barbaro, B., Brotherton, J.M.L., 2014. Assessing HPV vaccine coverage in Australia by geography and socioeconomic status: are we protecting those most at risk? Aust. N. Z. J. Publ. Health 38, 419-423. https://doi.org/10.1111/1753-6405.12218.

Pike, L.R.G., Royce, T.J., Mahal, A.R., Kim, D.W., Hwang, W.L., Mahal, B.A., et al., 2020. Outcomes of HPV-associated squamous cell carcinoma of the head and neck: impact of race and socioeconomic status. J. Natl. Compr. Cancer Netw. 18, 177-184. https://doi.org/10.6004/jnccn.2019.7356.

INCA, 2019. Instituto Nacional de Câncer José Alencar Gomes da Silva. Estimativa 2020 incidência de câncer no Brasil / Instituto Nacional de Câncer José Alencar Gomes da Silva. Rio de Janeiro.

McDougall, J.A., Madeleine, M.M., Daling, J.R., Li, C.I., 2007. Racial and ethnic disparities in cervical cancer incidence rates in the United States, 1992-2003.
Cancer Casuses Control 18 (10), 1175-1186. https://doi.org/10.1007/s10552-0079056-y.

de Sanjosé, S., Diaz, M., Castellsagué, X., Clifford, G., Bruni, L., Muñoz, N., et al., 2007. Worldwide prevalence and genotype distribution of cervical human papillomavirus DNA in women with normal cytology: a meta-analysis. Lancet. Infect. Dis 7 (7), 453-459. https://doi.org/10.1016/S1473-3099(07)70158-5.

IBGE, 2016. Pesquisa nacional por amostra de domicílios : síntese de indicadores 2015 / IBGE, Coordenação de Trabalho e Rendimento. Rio de Janeiro.

Moser, A.M., Reggiani, C., Urbanetz, A., 2007. Risky sexual behavior among university students in health science courses. Rev. Assoc. Med. Bras. 53, 116-121. https://doi. org/10.1590/S0104-42302007000200014.

Machalek, D.A., Chow, E.P.F., Garland, S.M., Wigan, R., Cornall, A.M., Fairley, C.K., et al., 2017. Human papillomavirus prevalence in unvaccinated heterosexual men after a national female vaccination program. J. Infect. Dis. 215, 202-208. https:// doi.org/10.1093/infdis/jiw530. 